\title{
Percent Recovered Over Dosing Interval Normalized by Body Mass Index
}

National Cancer Institute

\section{Source}

National Cancer Institute. Percent Recovered Over Dosing Interval Normalized by Body

Mass Index. NCI Thesaurus. Code C102387.

The percentage of the administered dose that is recovered from the specimen type specified in PPSPEC, between doses (TAU) divided by the body mass index. 